\title{
Effect of hydroxyselenomethionine on lactation performance, blood profiles, and transfer efficiency in early-lactating dairy cows
}

\author{
Y. Li ${ }^{1,2}$ J. X. Liu, ${ }^{1}$ J. L. Xiong, ${ }^{1}$ Y. M. Wang, ${ }^{3}$ W. X. Zhang, ${ }^{4}$ and D. M. Wang ${ }^{1 *}$ \\ ${ }^{1}$ Institute of Dairy Science, MoE Key Laboratory of Molecular Animal Nutrition, College of Animal Sciences, Zhejiang University, \\ Hangzhou 310058, P. R. China \\ ${ }^{2}$ Zhoukou Vocational and Technical College, Zhoukou 466000, P. R. China \\ ${ }^{3}$ Novus International Trading (Shanghai) Co. Ltd., Shanghai 200080, P. R. China \\ ${ }^{4}$ Henan University of Animal Husbandry and Economy, Zhengzhou 450046, P. R. China
}

\section{ABSTRACT}

The current study investigated the effects of hydroxyselenomethionine (HMBSe), a novel organic selenium (Se) additive, on lactation performance, blood profiles, antioxidative status, and transfer efficiency of Se in early-lactation dairy cows. Sixty multiparous early-lactating dairy cows with similar days in milk $(57 \mathrm{~d}$; standard deviation $=9.9)$ and milk yield $(36.5$ $\mathrm{kg} / \mathrm{d}$; standard deviation $=1.42$ ) were fed a basal diet containing $0.04 \mathrm{mg}$ of $\mathrm{Se} / \mathrm{kg}$ (dry matter basis). These cows were assigned to 1 of 4 groups following a randomized complete block design as follows: control (basal diet) or HMBSe addition (0.1, 0.3, or $0.5 \mathrm{mg}$ of Se/ $\mathrm{kg}$ of dry matter). The experiment lasted for $13 \mathrm{wk}$, with the first week as adaptation. The results showed that milk yields (raw, protein, and lactose) and feed efficiency were improved in a quadratic manner following increased dietary HMBSe addition, whereas energycorrected milk, $4 \%$ fat-corrected milk, and total solid yields tended to be enhanced quadratically. In terms of whole-blood variables, red blood cell and white blood cell levels were increased quadratically, whereas hemoglobin concentration increased linearly with increased HMBSe addition. Plasma nonesterified fatty acid concentrations tended to increase linearly along with HMBSe addition. Plasma superoxide dismutase activity increased quadratically with increased HMBSe addition. The total antioxidant capacity in plasma tended to improve quadratically when cows were fed more HMBSe. Moreover, plasma malondialdehyde concentrations of dairy cows tended to decrease in a quadratic manner when dietary HMBSe increased. The Se concentrations in milk, plasma, and milk/plasma

Received January 2, 2019

Accepted March 27, 2019.

*Corresponding author: wdm@zju.edu.cn ratio increased linearly following increased HMBSe addition. In conclusion, HMBSe improved lactation performance, health status, and milk Se concentrations in early-lactating dairy cows.

Key words: hydroxyselenomethionine, lactation performance, blood profile, early-lactating cow

\section{INTRODUCTION}

Selenium (Se) is an essential trace element for dairy cows. Feeding Se increases milk production, feed digestibility, antioxidative capacity, and immune function of dairy cows in different physiological stages (Ceballos et al., 2009). In dairy feeding systems, Se can be supplied to cows in inorganic or organic forms. Inorganic Se, such as sodium selenite, is more prone to dietary and environmental antagonisms (Suksombat et al., 2011). Organic Se, such as yeast Se and selenomethionine, has been widely used due to its lower toxicity and higher bioavailability (Phipps et al., 2008).

Compared with organic Se, which is widely used to provide Se to the dairy industry, Se chelated to 2-hydroxy-4-methylthiobutanoic acid (HMBSe) is a new type of feed additive (Kumar et al., 2017). However, 2-hydroxy-4-(methylthio) butanoic acid (HMB) has been used extensively as a source of supplemental Met (St-Pierre and Sylvester, 2005), and chelated organic trace minerals (zinc, copper, manganese, or iron) have been studied in dairy cows (Conti et al., 2010). A recent study found that feeding HMBSe improves the lactation performance and antioxidant status in mid-lactating dairy cows (Sun et al., 2017). However, the role of HMBSe in lactation performance and health status in early-lactating cows is not currently known. Therefore, the objectives of the present study were to determine the effects of HMBSe supplementation on milk production, antioxidative status, immunity, and its transfer efficiency into milk to evaluate its potential application in the dairy feed industry. 


\section{MATERIALS AND METHODS}

The present study was conducted at the Hangjiang Dairy Farm (Hangzhou, China). All procedures were conducted using protocols approved by the Institute of Dairy Science of Zhejiang University (Hangzhou, China). All animals used in the current study were managed according to standards established by the Institute of Dairy Science, Zhejiang University (Hangzhou, China). All cows were housed in individual tiestalls and milked daily at 0600,1400 , and $2000 \mathrm{~h}$. Throughout the entire experimental period, the health condition of the cows was monitored and recorded.

\section{Animal, Diets, and Experimental Design}

Sixty multiparous early-lactating dairy cows with DIM of $57 \pm 9.9$ (mean $\pm \mathrm{SD}$ ), milk production of 36.5 $\pm 1.42 \mathrm{~kg} / \mathrm{d}$ (mean $\pm \mathrm{SD}$ ), and average BW of $590 \pm$ $52.5 \mathrm{~kg}$ (mean $\pm \mathrm{SD}$ ) were divided into 15 blocks based on DIM, milk production, and BW. The cows were randomly assigned within the block to 1 of 4 dietary treatments as follows: no Se added (control) and 0.1, 0.3 , and $0.5 \mathrm{mg}$ of $\mathrm{Se} / \mathrm{kg}$ on a DM basis. The HMBSe (white particles; Se, 2,000 $\mathrm{mg} / \mathrm{kg}$ ) was provided by Shanghai Yanhua Bio-Tech Co. Ltd. (Shanghai, China) and Novus International Inc. (Shanghai, China). All cows received the same diet (TMR) containing 0.04 $\mathrm{mg} / \mathrm{kg}$ Se (DM basis). The composition and nutrient contents of the feed ingredients are presented in Table 1. All ingredients were mixed in a TMR and offered to individual cows 3 times per day. The HMBSe was fed using a top-dressed method into TMR. All cows had free access to water throughout the entire experiment.

\section{Sampling, Measurement, and Analyses}

The offered and refused feed amounts were recorded on the third and fourth days every other week throughout the entire experimental period. Samples from cows fed TMR and orts were collected on the recording days to calculate the DMI (West et al., 2003). The sample preparation and analysis were performed using methods described previously (Wang et al., 2013a). All samples were dried in a forced-air oven at $60^{\circ} \mathrm{C}$ for $48 \mathrm{~h}$ and placed in sealed containers until analysis. Samples were ground to pass a 2-mm Wiley mill screen (Arthur H. Thomas, Philadelphia, PA) and then through a 1-mm screen in a Cyclotec mill (Tecator 1093, Tecator, Höganäs, Sweden). Feed samples were analyzed for DM, CP (method no. 988.05; AOAC, 1990), NDF, and ADF as described previously (Van Soest et al., 1991).

Milk yield was measured on the third and fourth days in each experimental week, and milk samples were collected from each milking using Waikato Milking Systems meters (Waikato Milking Systems NZ Ltd., Hamilton, New Zealand). Milk samples were composited proportionally (4:3:3, composite) for analysis of content (Wang et al., 2013b). A 50-mL subsample was treated with bronopol (milk preservative; D\&F Control Systems, San Ramon, CA) and stored at $4^{\circ} \mathrm{C}$ for later determination of fat, true protein, and lactose by infrared analysis (MilkoScan, Foss Electric, Hillerød, Denmark; Laporte and Paquin, 1999). The MUN was determined using the diacetylmonoxime-binding assay as described in a previous study (Bashtani et al., 2009). Milk subsamples obtained on the fourth day of experimental wk 4, 8, and 12 were frozen and stored at $-20^{\circ} \mathrm{C}$ for the determination of Se concentration using the method reported in a previous study by Heard et al. (2007).

Blood samples $(10 \mathrm{~mL})$ were collected from the coccygeal vein of each cow $3 \mathrm{~h}$ after the morning feeding on the third day of wk 4, 8, and 12 (Wang et al., 2013b). The collected blood was then centrifuged at $3,000 \times$ $g$ for 10 min at $4^{\circ} \mathrm{C}$ to collect serum, which was frozen at $-20^{\circ} \mathrm{C}$ until analysis. Serum samples were later thawed and analyzed for quantification of albumin, alkaline phosphatase, $\gamma$-glutamyl transferase, aspartate amino transferase, BUN, cholesterol, globulin, glucose,

Table 1. Ingredients and chemical composition of the basal diet $(\%$, as-fed DM, unless otherwise noted)

\begin{tabular}{lc}
\hline Item & Value \\
\hline Ingredient & \\
Ground corn & 21.0 \\
Soybean meal, $44 \% \mathrm{CP}$ & 9.0 \\
Barley & 3.5 \\
Wheat bran & 2.0 \\
Dried distillers grains with solubles & 13.0 \\
Cottonseed meal & 4.5 \\
Corn silage & 12.0 \\
Alfalfa hay & 14.5 \\
Grass hay & 8.0 \\
Beet pulp & 8.0 \\
Premix & 4.5 \\
Nutrient composition, DM basis ${ }^{2}$ & \\
DM & 44.8 \\
CP & 16.4 \\
Ether extract & 2.63 \\
NDF & 36.6 \\
ADF & 23.6 \\
Selenium & 0.04 \\
Calcium & 0.73 \\
Phosphorus & 0.38 \\
Ash & 8.76 \\
NE ${ }^{3},{ }^{3}$ Mcal/kg & 1.65 \\
\hline
\end{tabular}

${ }^{1}$ Provided per kilogram of premix: $80,000-145,000 \mathrm{mg}$ of vitamin A; 20,000-39,000 mg of vitamin D; $\geq 700 \mathrm{IU}$ of vitamin E; $180-345 \mathrm{mg}$ of $\mathrm{Cu} ; 190-330 \mathrm{mg}$ of Fe; $950-1,800 \mathrm{mg}$ of $\mathrm{Zn} ; 350-650 \mathrm{mg}$ of $\mathrm{Mn} ; \geq 7 \%$ $\mathrm{Ca} ; \geq 1.3 \% \mathrm{P} ; \geq 1 \%$ Co.

${ }^{2}$ Calculated from the analyzed value of the dietary ingredients.

${ }^{3}$ Calculated based on MOA (2004). 
total protein, BHB, nonesterified fatty acids (NEFA), and glutathione peroxidase (GSH-px) according to methods described in previous studies (Davidson et al., 2008). The concentrations of total antioxidant capacity (T-AOC), superoxide dismutase (SOD), and malonaldehyde (MDA) in the plasma were measured by using previously reported methods (Benzie and Stain, 1996; Zhang et al., 2006). The determination of Se concentration in serum was the same as that in milk.

Additional blood samples from the coccygeal vein of experimental cows were prepared approximately 3 $\mathrm{h}$ after the morning feeding on the third day of wk 4, 8 , and 12 and immediately placed into a $10-\mathrm{mL}$ tube for whole-blood variable determination. Whole-blood samples were used to determine red blood cell (RBC) count, mean corpuscular hemoglobin, hemoglobin concentration, and white blood cell (WBC) count according to previously reported methods (Faggio, 2014). Neutrophil, lymphocyte, monocyte, and eosinophil counts were determined according to previously reported methods (da Silva et al., 1992).

\section{Calculations and Statistical Analysis}

The ECM and 4\% FCM were calculated as follows:

$$
\begin{aligned}
& \text { ECM }(\mathrm{kg} / \mathrm{d})=0.3246 \times \text { milk yield }(\mathrm{kg} / \mathrm{d})+12.86 \\
& \times \text { fat yield }(\mathrm{kg} / \mathrm{d})+7.04 \times \text { protein yield }(\mathrm{kg} / \mathrm{d}) \\
& 4 \% \mathrm{FCM}(\mathrm{kg} / \mathrm{d})=\text { milk yield }(\mathrm{kg} / \mathrm{d}) \\
& \times(0.4+15 \times \text { fat content } / 100)
\end{aligned}
$$

All data were analyzed using the MIXED procedure with repeated measurement with the covariance type $\mathrm{AR}(1)$ of the SAS software system (SAS Institute Inc., Cary, NC). A randomized incomplete block design with repeated measurements was used with week, treatment, treatment $\times$ week interaction, and block as the main factors. The effect of cow was included as a repeated measure. The results were reported as least squares means and standard error of the mean. Linear and quadratic effects of treatment were tested for feed intake, lactation performance, and plasma variables using orthogonal polynomial contrasts. Probability values of $P<0.05$ were used to define statistical significance, and $P<0.10$ and $P>0.05$ were defined as statistical trends.

\section{RESULTS}

\section{Feed Intake and Lactation Performance}

The results in terms of feed intake and lactation performance are shown in Table 2. The DMI did not differ across the treatments $(P>0.05)$. The yields of raw milk $(P=0.05)$, protein $(P=0.01)$, and lactose $(P=0.04)$ were increased in a quadratic manner following the increased Se addition. The $4 \%$ FCM $(P=$ $0.08)$ and $\operatorname{ECM}(P=0.07)$ of the animals tended to increase quadratically when dietary HMBSe increased. In addition, feed efficiency was improved in a quadratic manner with increased HMBSe addition $(P=0.05)$. However, milk composition (fat, protein, and lactose)

\begin{tabular}{|c|c|c|c|c|c|c|c|}
\hline Item & \multicolumn{4}{|c|}{ HMBSe, mg/kg (DM basis) } & SEM & \multicolumn{2}{|c|}{$P$-value ${ }^{1}$} \\
\hline DMI, kg/d & 20.8 & 20.6 & 20.7 & 20.5 & 1.40 & 0.12 & 0.84 \\
\hline Milk & $33.6^{\mathrm{b}}$ & $35.3^{\mathrm{a}}$ & $35.9^{\mathrm{a}}$ & $33.3^{\mathrm{b}}$ & 1.07 & 0.57 & 0.05 \\
\hline $4 \% \mathrm{FCM}$ & $32.8^{\mathrm{b}}$ & $34.4^{\mathrm{a}}$ & $34.8^{\mathrm{a}}$ & $32.4^{\mathrm{b}}$ & 1.16 & 0.82 & 0.08 \\
\hline ECM & $35.0^{\mathrm{b}}$ & $36.0^{\mathrm{a}}$ & $36.5^{\mathrm{a}}$ & $34.8^{\mathrm{b}}$ & 1.06 & 0.75 & 0.07 \\
\hline Lactose & $1.68^{\mathrm{b}}$ & $1.75^{\mathrm{a}}$ & $1.76^{\mathrm{a}}$ & $1.70^{\mathrm{b}}$ & 0.26 & 0.14 & 0.04 \\
\hline TS & 4.43 & 4.57 & 4.60 & 4.44 & 0.75 & 0.62 & 0.08 \\
\hline \multicolumn{8}{|c|}{ Milk content, $\mathrm{g} / 100 \mathrm{~g}$} \\
\hline Protein & 3.19 & 3.25 & 3.21 & 3.26 & 0.41 & 0.24 & 0.95 \\
\hline Fat & 3.85 & 3.81 & 3.81 & 3.86 & 0.54 & 0.68 & 0.20 \\
\hline Lactose & 5.02 & 5.06 & 5.03 & 5.03 & 0.18 & 0.73 & 0.16 \\
\hline TS & 13.2 & 13.2 & 13.2 & 13.3 & 0.94 & 0.86 & 0.64 \\
\hline
\end{tabular}
was not affected by HMBSe addition $(P>0.05)$.

Table 2. Effects of dietary hydroxyselenomethionine (HMBSe) on DMI, milk production, and milk composition in early-lactating dairy cows (15 animals/group)

${ }^{\mathrm{a}, \mathrm{b}}$ Values within a row with different superscripts are significantly different $(P<0.05)$.

${ }^{1} \mathrm{~L}=$ linear; $\mathrm{Q}=$ quadratic. 
Table 3. Effects of dietary hydroxyselenomethionine (HMBSe) on plasma variables in early-lactating dairy cows (15 animals/group)

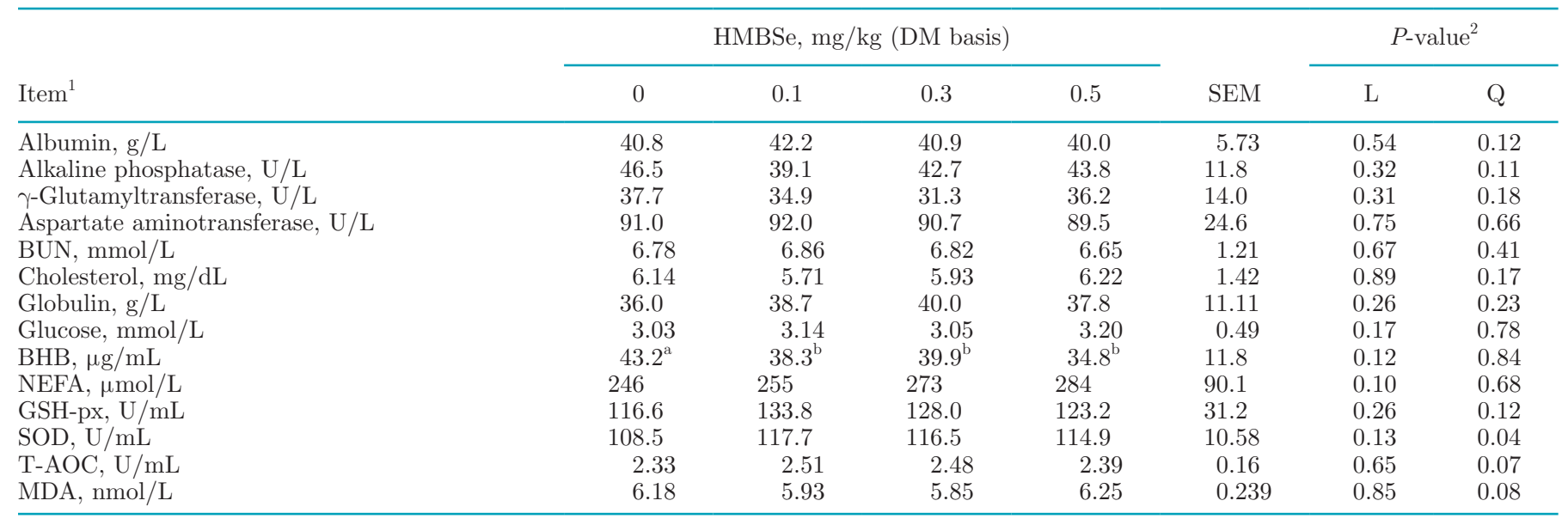

$\overline{\mathrm{a}, \mathrm{b}}$ Values within a row with different superscripts are significantly different $(P<0.05)$.

${ }^{1} \mathrm{NEFA}=$ nonesterified fatty acids; GSH-px = glutathione peroxidase; SOD = superoxide dismutase; T-AOC = total antioxidant capacity; MDA $=$ malondialdehyde.

${ }^{2} \mathrm{~L}=$ linear; $\mathrm{Q}=$ quadratic.

\section{Variables in Plasma and Whole Blood of Dairy Cows}

The effects of additional HMBSe on plasma variables are summarized in Table 3. The plasma NEFA concentrations tended to increase linearly along with HMBSe addition $(P=0.10)$. The plasma SOD activity increased quadratically with increased HMBSe addition $(P=0.04)$. In addition, T-AOC in plasma tended to improve quadratically when cows were fed more HMBSe $(P=0.07)$. Moreover, plasma MDA concentrations of dairy cows tended to decrease in a quadratic manner when dietary HMBSe increased $(P=0.08)$. The other plasma variables were not affected by HMBSe addition $(P>0.10)$. The effects of HMBSe addition on wholeblood variables are shown in Table 4 . The RBC $(P=$ $0.03)$ and WBC $(P=0.01)$ counts in the whole blood increased in a quadratic manner with linearly increased HMBSe supplementation, and hemoglobin concentrations in whole blood increased linearly with HMBSe addition $(P=0.01)$. The other blood variables were not changed by HMBSe addition $(P>0.05)$.

\section{Se Concentrations in Plasma and Milk of Early-Lactating Dairy Cows}

The effects of HMBSe supplementation on Se distribution in biofluids of dairy cows are presented in Table 5 . The Se concentrations in milk $(P<0.01)$, plasma $(P$ $<0.01)$, and ratio of milk to serum $(P<0.01)$ increased linearly with HMBSe supplementation increases.

\section{DISCUSSION}

Hydroxyselenomethionine is a newly developed organic Se source. A recent study found that in midlactating cows, supplementation of HMBSe improved milk yield and fat yield in a linear manner, which was partly attributed to its role in improving oxidative status (Sun et al., 2017). Relative to mid-lactating dairy cows, early-lactating cows are more prone to oxidative stress, which may be attributed to an energy consumption-excretion imbalance. In contrast to the study conducted by Sun et al. (2017), the present study

Table 4. Effects of dietary hydroxyselenomethionine (HMBSe) on blood variables in early-lactating dairy cows (15 animals/group)

\begin{tabular}{|c|c|c|c|c|c|c|c|}
\hline \multirow[b]{2}{*}{ Item } & \multicolumn{4}{|c|}{ HMBSe, mg/kg (DM basis) } & \multirow[b]{2}{*}{ SEM } & \multicolumn{2}{|c|}{$P$-value ${ }^{1}$} \\
\hline & 0 & 0.1 & 0.3 & 0.5 & & $\mathrm{~L}$ & Q \\
\hline Red blood cells, $\times 10^{6} / \mu \mathrm{L}$ & $6.60^{\mathrm{b}}$ & $7.51^{\mathrm{a}}$ & $7.60^{\mathrm{a}}$ & $7.19^{\mathrm{b}}$ & 1.00 & 0.02 & 0.03 \\
\hline Hemoglobin, g/dL & $10.9^{\mathrm{b}}$ & $12.6^{\mathrm{a}}$ & $12.7^{\mathrm{a}}$ & $13.3^{\mathrm{a}}$ & 1.81 & 0.01 & 0.42 \\
\hline White blood cells, $\times 10^{3} / \mu \mathrm{L}$ & $13.7^{\mathrm{b}}$ & $17.3^{\mathrm{a}}$ & $19.5^{\mathrm{a}}$ & $14.4^{\mathrm{b}}$ & 5.71 & 0.26 & 0.01 \\
\hline Neutrophils, $\times 10^{3} / \mu \mathrm{L}$ & 5.24 & 4.17 & 5.25 & 6.36 & 4.29 & 0.62 & 0.29 \\
\hline Lymphocytes, $\times 10^{3} / \mu \mathrm{L}$ & 6.59 & 7.50 & 7.62 & 4.60 & 5.54 & 0.48 & 0.19 \\
\hline Monocytes, $\times 10^{3} / \mu \mathrm{L}$ & 1.10 & 0.66 & 0.95 & 0.91 & 0.84 & 0.60 & 0.33 \\
\hline
\end{tabular}

$\overline{\mathrm{a}, \mathrm{b}}$ Values within a row with different superscripts are significantly different $(P<0.05)$.

${ }^{1} \mathrm{~L}=$ linear; $\mathrm{Q}=$ quadratic. 
found that milk production increased in a quadratic manner with HMBSe addition. The disagreement may be attributed to Sun et al. (2017) using mid-lactating dairy cows compared with early-lactating dairy cows in the present study. Thus, the variation in the results may be due to the different physiological periods of experimental animals. To the best of our knowledge, the present study is the first to evaluate the effects of HMBSe addition on lactation performance of cows in the early-lactating period. Juniper et al. (2006) found that Se yeast addition $(0.27,0.33$, and $0.40 \mathrm{mg} / \mathrm{kg}$ of $\mathrm{DM}$ ) did not affect lactation performance (yield and composition) in early-lactating animals. Thus, the present study suggested that HMBSe is more efficient than Se yeast in improving milk production of early-lactating dairy cows when it is added in an appropriate dose. In summary, HMBSe addition improved lactation performance in both early- and mid-lactating dairy cows without affecting their DMI. However, early-lactating cows may be more sensitive to the dosage of HMBSe supplementation. These data indicated that the optimized HMBSe addition in early-lactating cows should be less than $0.5 \mathrm{mg} / \mathrm{kg}$ (DM basis) to improve lactation performance.

Glutathione peroxidase is an important Se-containing enzyme in mammals in terms of reducing hydrogen peroxides. Increased plasma Se concentrations led to improved antioxidant capacity (indicated by increased activities of SOD, GSH-px, and T-AOC as well as reduced MDA concentration) of dairy cows (Pilarczyk et al., 2012; Sun et al., 2017). A previous study reported higher GSH-px, SOD, and T-AOC as well as lower MDA in plasma collected from cows fed increased HMBSe (Sun et al., 2017). These results were partly consistent with the present study showing increased antioxidant capacity (plasma SOD and T-AOC) and reduced peroxidation product (plasma MDA) following dietary HMBSe addition (Cao et al., 2014; Gong et al., 2014). However, plasma GSH-px activity was not changed by HMBSe supplementation $(P=0.12)$. The effects of Se on GSH-px depend on many factors, such as DIM, dietary Se content, and Se status of the ani- mals (Knowles et al., 1999; Ortman and Pehrson, 1999). Although dietary Se concentrations in the basal diet in the present study were similar to those reported by Sun et al. (2017), the plasma Se concentration of cows in the control group was higher in the present study (83 $\mu \mathrm{g} / \mathrm{kg}$ Se in plasma) than that reported by Sun et al. (2017; $70 \mu \mathrm{g} / \mathrm{kg}$ Se in plasma), which may be due to the cows in the study by Sun et al. (2017) being in a less stressed condition (mid-lactating stage). This evidence indicated that HMBSe addition in early-lactating cows may not affect plasma GSH-px status, which agreed with Cerri et al. (2009), who found that dietary sodium selenite or Se yeast in early-lactating cows does not affect GSH-px activity in plasma. Thus, the effects of HMBSe on plasma GSH-px activity may be varied in different physiological stages. In brief, HMBSe addition improved antioxidant capacity of dairy cows. The increased NEFA and BHB concentrations in plasma indicated alleviated body reserve mobilization. A previous study has reported higher NEFA and lower BHB concentrations in plasma when yeast Se and sodium selenite are introduced to mid-lactating cows (Calamari et al., 2011), and cows fed Se have better energy and protein metabolism during the summer season (Calamari et al., 2011). The similarity between the results of Calamari et al. (2011) and those of the present study suggests that Se addition may relieve stress caused by thermal and peak period disorder. In summary, the increased milk yield caused by HMBSe addition may be partly attributed to the improved antioxidative capacity and body reserve mobilization.

The WBC and RBC counts in the blood indicate immunological function of dairy cows (Schulz et al., 2015; Kvidera et al., 2017), and increased WBC and $\mathrm{RBC}$ counts in whole blood indicate an improved immunity (Schulz et al., 2015; Kvidera et al., 2017). In the present study, the quadratically increased WBC and RBC counts in blood suggested an improved immunity of dairy cows fed median levels of HMBSe $(0.1$ and 0.3 $\mathrm{mg} / \mathrm{kg})$. A previous study found limited effects of Se addition on RBC and WBC in blood of mid-lactating dairy cows (Calamari et al., 2011). There are several

Table 5. Effects of dietary hydroxyselenomethionine (HMBSe) on selenium concentrations $(\mu \mathrm{g} / \mathrm{L})$ in milk and plasma of early-lactating dairy cows (15 animals/group)

\begin{tabular}{lcccccccc}
\hline & \multicolumn{3}{c}{ HMBSe, $\mathrm{mg} / \mathrm{kg}(\mathrm{DM}$ basis $)$} & & \multicolumn{2}{c}{$P$-value $^{1}$} \\
\cline { 2 - 4 } \cline { 7 - 9 } Item & 0 & 0.1 & 0.3 & 0.5 & & SEM & L & \multirow{2}{*}{$\mathrm{Q}$} \\
\hline Milk & $25.9^{\mathrm{c}}$ & $33.9^{\mathrm{b}}$ & $38.5^{\mathrm{ab}}$ & $43.8^{\mathrm{a}}$ & 9.28 & $<0.01$ & 0.51 \\
Plasma & $82.8^{\mathrm{b}}$ & $89.5^{\mathrm{b}}$ & $99.0^{\mathrm{a}}$ & $104^{\mathrm{a}}$ & 12.9 & $<0.01$ & 0.31 \\
Milk/plasma ratio & $31.6^{\mathrm{c}}$ & $38.3^{\mathrm{b}}$ & $41.5^{\mathrm{ab}}$ & $48.7^{\mathrm{a}}$ & & 11.0 & $<0.01$ & 0.32 \\
\hline
\end{tabular}

${ }^{\mathrm{a}-\mathrm{c}}$ Values within a row with different superscripts are significantly different $(P<0.05)$.

${ }^{1} \mathrm{~L}=$ linear; $\mathrm{Q}=$ quadratic. 
possibilities for the variations between the previous study (Calamari et al., 2011) using mid-lactating cows and the present study using early-lactating cows. First, the immunological status of early- and mid-lactating cows is different (Stevens et al., 2011). Moreover, the different Se additives were used in the 2 studies [sodium selenite and Se yeast in Calamari et al. (2011) and HMBSe in the present study]. To the best of our knowledge, the present study is the first to report the positive effects of dietary Se addition on RBC and WBC profiles in blood. It has been previously reported that $\mathrm{RBC}$ membrane integrity can be linked to the density of RBC in whole blood and antioxidant status in humans (Lubrano et al., 2000). Thus, HMBSe may improve $\mathrm{RBC}$ and $\mathrm{WBC}$ in the blood through reducing oxidative stress and maintaining membrane integrity of RBC of dairy cows. Moreover, as RBC and WBC in blood are indirect indicators of the immunological status of dairy cows, future studies should be conducted to understand whether dietary HMBSe addition changes functional gene expression of RBC and WBC in dairy cows as well as gene expression of immune cells (Wang et al., 2013c) and cytokine levels (Martin et al., 2016) to further describe the immunology status change in dairy cows.

Selenium status is an important trait for dairy cows and can be assessed by evaluating its concentrations in plasma. A previous survey concluded that adequate plasma Se concentration in dairy cows is more than $79 \mu \mathrm{g} / \mathrm{L}$ (Sivertsen et al., 2005). However, another study found that cows in different periods, including the dry period $(90 \mu \mathrm{g} / \mathrm{L})$, transition $(130 \mu \mathrm{g} / \mathrm{L})$, and early lactation $(100 \mu \mathrm{g} / \mathrm{L})$, have different requirements for Se (Gong and Xiao, 2016). In the present study, the plasma Se concentration of early-lactating cows fed a basal diet was $82.8 \mu \mathrm{g} / \mathrm{L}$, which was lower than that of early-lactating cows as reported by Gong and Xiao (2016). Despite individual variation, the report by Gong and Xiao (2016) and the increased milk yield of cows with increased HMBSe addition in the present study suggest that Se provided in the basal diet was not sufficient for cows in the current experimental condition. The responses of Se concentrations in plasma to dietary HMBSe addition, milk, and milk/plasma ratio were similar to those reported by Sun et al. (2017), indicating that early- and mid-lactating cows have similar responses to HMBSe accumulation in the plasma and milk. Compared with Wang et al. (2009), who fed diets containing a similar dose of Se-yeast $(0.15,0.30$, and $0.45 \mathrm{mg}$ of $\mathrm{Se} / \mathrm{kg}$ of $\mathrm{DM}$ ) to early-lactating dairy cows, the milk Se concentrations of HMBSe-fed cows in the current study seemed to be lower. This indicated that in early-lactating cows, transfer efficiency of dietary HMBSe to milk is lower than that of Se-yeast, which could be attributed to the different chemical structure of the 2 Se additives. Thus, further studies should be performed to investigate why Se-yeast had better milk transfer efficiency than HMBSe and why linearly increased HMBSe addition improves the Se ratio of milk/ plasma.

\section{CONCLUSIONS}

The present study found that HMBSe supplementation improved the lactation performance, health status, and Se ratio of milk/plasma of cows in the early-lactating stage. The present study indicated that HMBSe is a potential Se source to improve performance and food quality in early-lactating cows.

\section{ACKNOWLEDGMENTS}

This research was supported by grants from the National Key Research and Development Program of China (2018YFD0501604), Fundamental Research Funds for the Central Universities (2019FZA6015), and China Agriculture Research System (CARS-37). The authors acknowledge the students of the Institute of Dairy Science Zhejiang University (Hangzhou, China) for their help with sample preparation and analysis.

\section{REFERENCES}

AOAC (Association of Official Analytical Chemists). 1990. Official Methods of Analysis. 15th ed. AOAC, Arlington, VA.

Bashtani, M., H. Farhangfar, H. Naeimipour, and M. R. Asghari. 2009. Application of milk urea nitrogen index (MUN I) for monitoring protein nutrition status in lactating dairy cow. J. Agric. Sci. Nat. Resour. 16:110-118.

Benzie, I. F. F., and J. J. Stain. 1996. The ferric reducing ability of plasma (FRAP) as a measure of "antioxidant power": The FRAP assay. Anal. Biochem. 239:70-76.

Calamari, L., F. Petrera, F. Abeni, and G. Bertin. 2011. Metabolic and hematological profiles in heat stressed lactating dairy cows fed diets supplemented with different selenium sources and doses. Livest. Sci. 142:128-137.

Cao, J., F. Guo, L. Zhang, B. Dong, and L. Gong. 2014. Effects of dietary selenomethionine supplementation on growth performance, antioxidant status, plasma selenium concentration, and immune function in weaning pigs. J. Anim. Sci. Biotechnol. 5:46.

Ceballos, A., J. Sánchez, H. Stryhn, J. B. Montgomery, H. W. Barkema, and J. J. Wichtel. 2009. Meta-analysis of the effect of oral selenium supplementation on milk selenium concentration in cattle. J. Dairy Sci. 92:324-342.

Cerri, R. L., H. Rutigliano, F. Lima, D. Araújo, and J. Santos. 2009 Effect of source of supplemental selenium on uterine health and embryo quality in high-producing dairy cows. Theriogenology 71:1127-1137.

Conti, G., G. Castillo, M. Gallardo, S. Toffano, and M. Vazquez-Anon. 2010. Supplementation of methionine hydroxy analog, trace mineral chelates and dietary antioxidants in the diet of dairy cows for milk production, milk composition, and hoof status. J. Dairy Sci. 93(Suppl. 1):718. (Abstr.)

da Silva, R. G., M. J. da Costa, and A. G. Sobrinho. 1992. Influence of hot environments on some blood variables of sheep. Int. J. Biometeorol. 36:223-225. 
Davidson, S., B. A. Hopkins, J. Odle, C. Brownie, V. Fellner, and L. W. Whitlow. 2008. Supplementing limited methionine diets with rumen-protected methionine, betaine, and choline in early lactation Holstein cows. J. Dairy Sci. 91:1552-1559.

Faggio, C. 2014. Haematological and biochemical response of Mugil cephalus after acclimation to captivity. Cah. Biol. Mar. 55:31-36.

Gong, J., L. Ni, D. Wang, B. Shi, and S. Yan. 2014. Effect of dietary organic selenium on milk selenium concentration and antioxidant and immune status in midlactation dairy cows. Livest. Sci. 170:8490.

Gong, J., and M. Xiao. 2016. Selenium and antioxidant status in dairy cows at different stages of lactation. Biol. Trace Elem. Res. 171:89-93.

Heard, J. W., C. R. Stockdale, G. P. Walker, C. M. Leddin, F. R. Dunshea, G. H. McIntosh, P. M. Shields, A. McKenna, G. P. Young, and P. T. Doyle. 2007. Increasing selenium concentration in milk: Effects of amount of selenium from yeast and cereal grain supplements. J. Dairy Sci. 90:4117-4127.

Juniper, D. T., R. H. Phipps, A. K. Jones, and G. Bertin. 2006. Selenium supplementation of lactating dairy cows: Effect on selenium concentration in blood, milk, urine, and feces. J. Dairy Sci. 89:3544-3551.

Knowles, S. O., N. Grace, K. Wurms, and J. Lee. 1999. Significance of amount and form of dietary selenium on blood, milk, and casein selenium concentrations in grazing cows. J. Dairy Sci. 82:429-437.

Kumar, K., S. Lee, A. S. Bharadwaj, C. L. Browdy, M. Vazquez-Anon, and S. C. Bai. 2017. Effects of inorganic and chelated trace mineral $(\mathrm{Cu}, \mathrm{Zn}, \mathrm{Mn}$ and $\mathrm{Fe})$ premixes in marine rockfish, Sebastes schlegeli (Hilgendorf), fed diets containing phytic acid. Aquacult. Res. 48:4165-4173.

Kvidera, S. K., E. A. Horst, M. Abuajamieh, E. J. Mayorga, M. V. Fernandez, and L. H. Baumgard. 2017. Glucose requirements of an activated immune system in lactating Holstein cows. J. Dairy Sci. 100:2360-2374.

Laporte, M. F., and P. Paquin. 1999. Near-infrared analysis of fat, protein, and casein in cow's milk. J. Agric. Food Chem. 47:2600-2605.

Lubrano, R., G. Meloni, S. M. di Villahermosa, M. Morosetti, and M. Taccone-Gallucci. 2000. Red blood cell membrane oxidative damage and renal impairment in uremic patients under conservative treatment. Nutrition 16:86.

Martin, C. E., M. A. Paibomesai, S. M. Emam, J. Gallienne, B. C. Hine, K. A. Thompson-Crispi, and B. A. Mallard. 2016. Short communication: Cytokine profiles from blood mononuclear cells of dairy cows classified with divergent immune response phenotypes. J. Dairy Sci. 99:2364-2371.

MOA (Ministry of Agriculture of P. R. China). 2004. Feeding Standard of Dairy Cattle (NY/T 34-2004). MOA, Beijing, China.

Ortman, K., and B. Pehrson. 1999. Effect of selenate as a feed supplement to dairy cows in comparison to selenite and selenium yeast. J. Anim. Sci. 77:3365-3370.

Phipps, R. H., A. S. Grandison, A. K. Jones, D. T. Juniper, E. Ramos-Morales, and G. Bertin. 2008. Selenium supplementation of lactating dairy cows: Effects on milk production and total selenium content and speciation in blood, milk and cheese. Animal $2: 1610-1618$

Pilarczyk, B., D. Jankowiak, A. Tomza-Marciniak, R. Pilarczyk, P. Sablik, R. Drozd, A. Tylkowska, and M. Skólmowska. 2012. Selenium concentration and glutathione peroxidase (GSH-Px) activity in serum of cows at different stages of lactation. Biol. Trace Elem. Res. 147:91-96.

Schulz, K., J. Frahm, S. Kersten, U. Meyer, D. Reiche, H. Sauerwein, and S. Dänicke. 2015. Effects of elevated parameters of subclinical ketosis on the immune system of dairy cows: In vivo and in vitro results. Arch. Anim. Nutr. 69:113-127.

Sivertsen, T., G. Overnes, O. Osterås, U. Nymoen, and T. Lunder. 2005. Plasma vitamin E and blood selenium concentrations in Norwegian dairy cows: Regional differences and relations to feeding and health. Acta Vet. Scand. 46:177-191.

St-Pierre, N. R., and J. T. Sylvester. 2005. Effects of 2-hydroxy4-(methylthio) butanoic acid (HMB) and its isopropyl ester on milk production and composition by Holstein cows. J. Dairy Sci. 88:2487-2497.

Stevens, M. G., L. J. Peelman, B. De Spiegeleer, A. Pezeshki, G. R. Van De Walle, L. Duchateau, and C. Burvenich. 2011. Differential gene expression of the toll-like receptor- 4 cascade and neutrophil function in early- and mid-lactating dairy cows. J. Dairy Sci. 94:1277-1288.

Suksombat, W., A. Nanon, P. Klangnork, and J. Homkhao. 2011. Effects of Met-hydroxy analog plus MINTREX ${ }^{\circledR}$ dairy supplementation on performance of lactating dairy cows. J. Anim. Vet. Adv. 10:2814-2818

Sun, P., J. Wang, W. Liu, D. P. Bu, S. J. Liu, and K. Z. Zhang. 2017. Hydroxy-selenomethionine: A novel organic selenium source that improves antioxidant status and selenium concentrations in milk and plasma of mid-lactation dairy cows. J. Dairy Sci. 100:96029610.

Van Soest, P. J., J. B. Robertson, and B. A. Lewis. 1991. Symposium: Carbohydrate methodology, metabolism and nutritional implications in dairy cattle methods for dietary fiber, neutral detergent fiber and nonstarch polysaccharides in relation to animal nutrition. J. Dairy Sci. 74:4377-4384.

Wang, C., Q. Liu, W. Z. Yang, Q. Dong, X. M. Yang, D. C. He, P. Zhang, K. H. Dong, and Y. X. Huang. 2009. Effects of selenium yeast on rumen fermentation, lactation performance and feed digestibilities in lactating dairy cows. Livest. Sci. 126:239-244.

Wang, D. M., H. Y. Liu, C. Wang, J. X. Liu, and J. D. Ferguson. 2013a. Effects of rumen-protected gamma-aminobutyric acid on feed intake, performance and antioxidative status in transition cows. Livest. Sci. 153:66-72.

Wang, D. M., C. Wang, H. Y. Liu, J. X. Liu, and J. D. Ferguson. 2013b. Effects of rumen-protected $\gamma$-aminobutyric acid on feed intake, lactation performance, and antioxidative status in early lactating dairy cows. J. Dairy Sci. 96:3222-3227.

Wang, X. S., Y. Zhang, Y. H. He, P. P. Ma, L. J. Fan, Y. C. Wang, Y. I. Zhang, D. X. Sun, S. L. Zhang, C. D. Wang, J. Z. Song, and Y. Yu. 2013c. Aberrant promoter methylation of the CD4 gene in peripheral blood cells of mastitic dairy cows. Genet. Mol. Res. 12:6228-6239.

West, J. W., B. G. Mullinix, and J. K. Bernard. 2003. Effects of hot, humid weather on milk temperature, dry matter intake, and milk yield of lactating dairy cows. J. Dairy Sci. 86:232-242.

Zhang, X. Y., Y. L. Tan, L. Y. Cao, G. Y. Wu, Q. Xu, Y. Shen, and D. F. Zhou. 2006. Antioxidant enzymes and lipid peroxidation in different forms of schizophrenia treated with typical and atypical antipsychotics. Schizophr. Res. 81:291-300. 